\title{
Microscopic Characteristics Research about Eaglewood Based on the Theory of Digital Detection Technology
}

\author{
Zhuang $\mathrm{Li}^{1,3, a}$, Haifeng Wang ${ }^{2,3, \mathrm{~b}}$ and Kun Zhang ${ }^{2,3, \mathrm{c}^{*}}$ \\ ${ }^{1}$ Division of development and Planning, Hainan Tropical Ocean University, Sanya, Hainan, 572022, \\ China \\ ${ }^{2}$ College of Computer Engineering, Hainan Tropical Ocean University, Sanya, Hainan, 572022, China \\ ${ }^{3}$ Sanya Key Laboratory of Computer Vision, Hainan Tropical Ocean University, Sanya, Hainan, 572022, \\ China \\ ahitlz@163.com, bwyfxxz@163.com, ‘zk0588@163.com \\ *The corresponding author
}

Keywords: Microscopic characteristics; Digital detection; Detection of eaglewood; Cell structure.

\begin{abstract}
In this paper, the computer vision technology is applied to eaglewood microscopic characteristics of organization structure research, development of the automation and intelligence of eaglewood organizational structure measurement and identification technology. To explore the establishment of eaglewood microstructure, microscopic characteristics of eaglewood. Using computer vision technology eaglewood microscopic cell image research, from the microscopic characteristics of incense for detection and identification technology research.
\end{abstract}

\section{Introduction}

Eaglewood is commonly used in traditional Chinese Medicine, Dry wood resin containing Aquilaria sinensis(Lour) Gilg or A agallocha(Lour. )Roxb, due to the Department of wood, heartwood weight, water sink, gas smell, hence the name. The former production in our country, used to refer to Chinese eaglewood, also known as Hainan eaglewood, the main producing in Hainan, Guangxi and other places, the latter producing in countries such as Malaysia, Indonesia and Vietnam, used to refer to for the import of eaglewood.

In recent years, because of a serious shortage of resources, medical supply shortage, prices rise, higher than the value of gold, criminals took the opportunity to sell fake eaglewood, resulting in inferior products to occupy the market, even some herbs market, pharmaceutical companies and medical units have fake eaglewood, really cannot remember or false, seriously affecting the curative effect. Therefore, it is of a great significance for the quality inspection and identification of eaglewood.

But at present, most domestic quality and detection means for chemical testing, do all kinds of physical and chemical assay and identification method is relatively single, also need to consume and destroy a certain amount of samples, the rare and valuable eaglewood resources is also a kind of loss and waste. Computer vision called the eye of automation, compared with the traditional detection method, the application of machine vision for product testing is one of the biggest advantage is not to contact with the object is detected, uniform grading standards and detection speed fast. The computer application technology based on digital image feature detection technology at home and abroad, some rare wood, bamboo and intelligent quality detection is widely used, such as based on the study on the wood structure of the digital image processing system research, wood cell image feature extraction and image database already belong to a higher level of technology and innovation in the field of detection techniques, but in the detection process of eaglewood still belongs to the blank, so the project based on the application of technology in eaglewood testing and identifying the quality of field has innovative and of great value in research. With the fast development of computer application technology and the information age of today, explore a method based on digital image technology in 
the field of information technology, fast, accurate, low cost or lossless Aquilaria sinensis quality detection method for the identification of, for rich eaglewood detection means, improve the detection efficiency of eaglewood, eaglewood testing raw materials resources conservation has is of great significance and role. Therefore, carry out based on computer vision of eaglewood and microscopic features detection method research is to maintain the sustainable development in our province, the pharmaceutical industry for the production of and improve the competitiveness in the market, improve economic efficiency, and is of great practical significance to increase the income.

\section{Domestic and Foreign Similar Products and Technology}

Eaglewood due to the larger and natural resources are gradually reduced, and the planting cycle long, and Medicine Co., and thus more expensive, commercially available eaglewood counterfeitgoods, fast and accurate method for the identification of in drug testing has a vital role, the eaglewood and mixed identification of counterfeit goods mainly from the aspect of macroscopic, microscopic and physicochemical, thin layer chromatography (TLC) and derivative spectrum characteristics distinction. In the current edition of Pharmacopoeia of eaglewood quality control only stipulated the alcohol soluble extract content, due to the effects of alcohol soluble extract content of more factors, sometimes even high alcohol solution extracts content, but does not necessarily indicate its quality is excellent. So it should be used to measure the quality of the medicinal materials by multi way and multi index. Ya Tong in the paper to the eaglewood wood and its adulterants characters and the cells in cross-section characteristics, physical and chemical identification etc. has carried on the detailed contrast, puts forward the method for the identification of eaglewood. Jianli Zhong proposed an identification method for near infrared spectroscopy, according to eaglewood wood is fake, the establishment of near infrared spectrometric identification model, the method has advantages is simple, rapid, accurate and less dosage, no pollution etc..

Computer vision technology in the field of micro detection is widely used, in medical detection, blood cell microscopic cell image analysis has a 30 years history of the development of, abroad for recognition of the started earlier, for example, Coulter Gen.s blood cell analyzer of Beckman Coulter company by 3D-VCS technology, in close to the natural state of cells, when abnormal white blood cell classification, peripheral blood smear into which is equipped with a microscopic image analysis system for white cell morphological analysis and accurate classification and characteristics of domestic experts and Yang Xiaomin, white cell microscopic image of research, and the development of a microcomputer and a monochrome CCD of leukocyte automatic recognition and analysis system. In forestry, such as New Zealand Wood Cell Biotechnology Center scientists Rotorua the combination of field emission electron microscopy and environmental scanning electron microscopy, the wood cell along the texture expression more vivid. In 2004 and 2006, the Swiss Federal timber laboratory Zimmerman,: the microscope photographs of white fir, and based on the established model, the fiber filaments is observed the microscopic results and model were compared, which is the smallest micro fiber silk structure simulation is observed in cells. Professor Ma Yan of Northeast Forestry University was proposed. Through the cell to establish mathematical model to identify the species of wood of new ideas, and on basis of this theory, and the Northeast Forestry University professor hong-e Ren jointly proposed the digital cell characteristics of wood species recognition method based on.

\section{Research Contents and Key Technologies}

The content of our research includes: build eaglewood cell characteristics of and digital model of cell characteristics of eaglewood feature extraction and recognition technology research based on; testing equipment system design and software programming; construction of eaglewood digital measurement technology feature library. On the completion of the establishment of the mathematical model of digital eaglewood for feature extraction and recognition, the necessity to develop test platform design and manufacture equipment identification, provide identification equipment prototype and research reports. The main work has the following 4 aspects. 
The Establishment of Cell Model and the Digital Characteristics of Eaglewood. Through the extraction of eaglewood microscopic cell image, establish suitable to the eaglewood wood cell image processing algorithms, analysis, the establishment of mathematical model of the characteristics of eaglewood cells, according to the mathematical model were detected and analyzed.

Study on Feature Extraction and Recognition Technology of Eaglewood Cells Based on Mathematical Characteristics. Based on the general characteristics of the eaglewood wood cell structure, the study of microscopic cell image segmentation, feature extraction algorithm, to construct the digital characteristics, the establishment of eaglewood category feature parameters and recognition algorithm, microscopic differences of eaglewood and its adulterants, suitable for the study of eaglewood microscopic cell image identification algorithm. Provide test bench and process technology research report. The principle experiment is carried out, and the necessary test bench is developed. Prepare the product specification and arrange the necessary design documents.

Test equipment System Design and Software Programming. The aim of the project is using the digital image processing technique to study the eaglewood of microscopic characteristics, and based on this, the identification method and technology. To determine the specific functions and requirements of the detection system, studies and designs the detection equipment of the system overall structure and the working principle, research eaglewood microscopic features extraction and identification system configuration planning system in concrete implementation method of study automatic recognition and identification technology. Software development. Provide image detection platform and process technology research reports, run software.

The Construction Features of the Digital Library Eaglewood Detection Technology. Eaglewood cell structure of different types of technology, establish digital detection based on feature library.

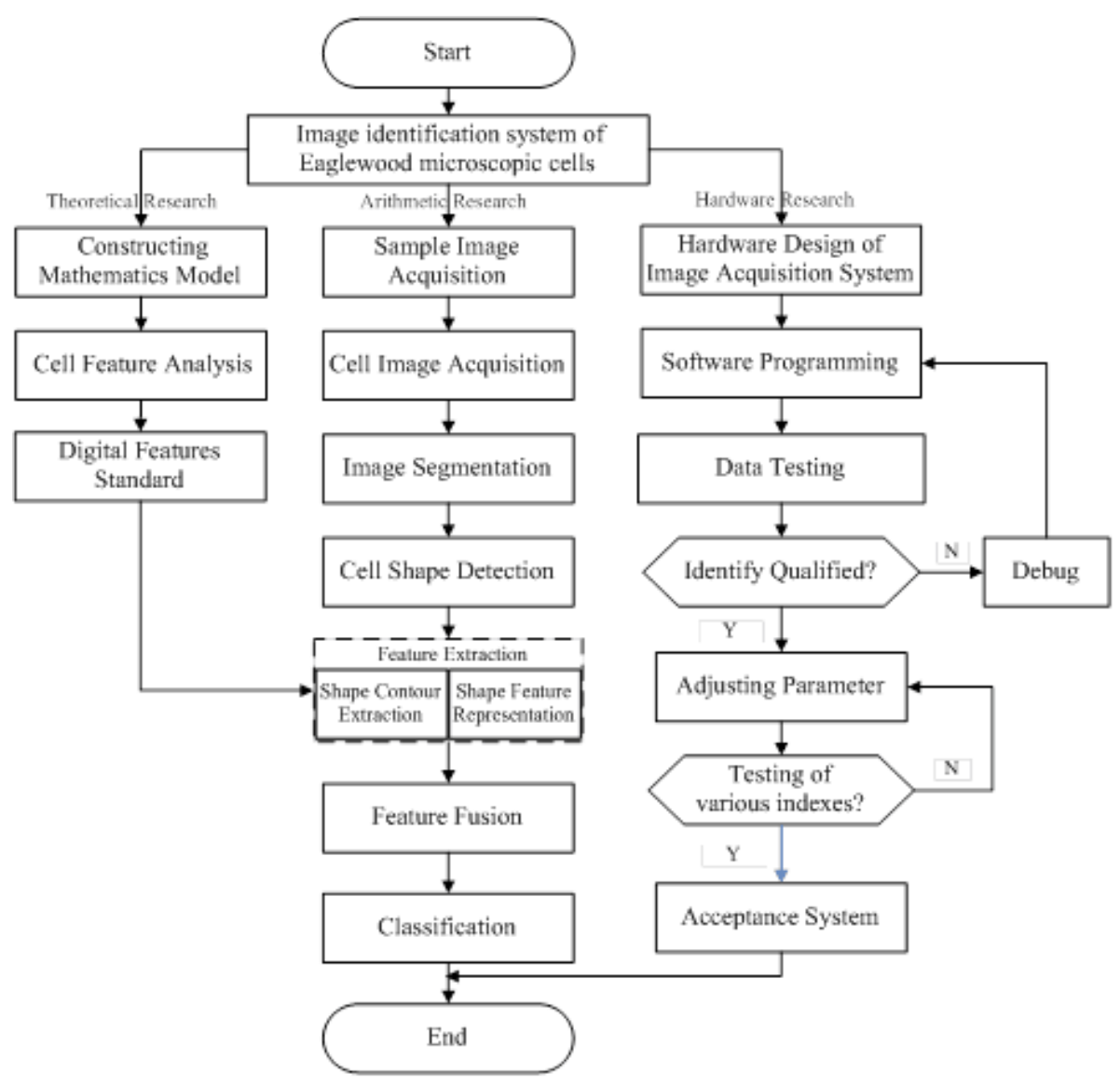

Figure 1. Technology roadmap 


\section{Key Technical Problems}

Construction of eaglewood cell model. It will feature extraction to lay the foundation, how to extract suitable microscopic cell image features and the classification methods, and how sample in sample library and a fast registration is the key problem of, the speed of image features are effective and categorization performance and registration algorithm can direct recognition accuracy and speed.

\section{Features and Innovations}

In this study, the computer vision technology is applied to eaglewood microscopic characteristics of organization structure research, development of the automation and intelligence of eaglewood organizational structure measurement and identification technology. To explore the establishment of eaglewood microstructure, microscopic characteristics of eaglewood. This research was conducted using computer vision technology eaglewood cell image, studied from incense detection and identification technology of micro features, this study has the following innovations and features: through the establishment of mathematical model of eaglewood microscopic cell image, description of the incense cell image from the point of view of mathematics, and provide a theoretical basis for the microscopic identification construction; eaglewood micro image acquisition experimental platform, converting the cell image information into digital information is easy to calculate and save the application of digital image processing technology, the establishment of Digital Library in the parameters of eaglewood, identification, the reference cell digital parameters of digital characteristic parameters of cells in comparison with the database, which not only saves the storage space, improve the recognition speed, and give full play to the high resolution image processing technology, flexible sample Features, with high speed and high accuracy of artificial recognition, the construction of the experimental platform for other quality detection play a reference role. Methods for feature extraction and classification of this study is innovative, intends to use level set method to extract cells, shape of the sample database is established and through the feature extraction method establishment of the sample characteristics of the library, for the recognition of eaglewood samples to be, after extracting the shape features, will be recognition of shape feature and shape feature in sample library of sample characteristics matching, similarity calculation, and the extracted features and the feature of sample library matching, to determine its category. This scheme can ensure the accuracy of the classification to the maximum extent, and increase the speed.

\section{Summary}

The research uses the theory first, the formation of problem induction, theoretical research, algorithm design, simulation and experimental study of the technical route. The project hopes to use existing eaglewood detection and recognition of achievements in scientific research, combined with the computer vision technology and information theory knowledge, through the study of eaglewood microscopic cell image, extraction suitable for eaglewood characteristic parameter for describing the digital characteristics, using the computer to realize to the eaglewood wood species and the authenticity of identification, and to address the problems encountered by artificial intelligence in the field of image recognition.

First, to the eaglewood wood microscopic cell image analysis, cell mathematical model is established, and visual identification of existing research systematically classified and analyzed, on the basis of combining the characteristics of the visual system proposed feasible and can meet the real-time requirements of feature extraction method. In-depth analysis the feature extraction and feature fusion algorithm, and the existing problems, proposed for eaglewood features digital feature parameters extraction and identification scheme, and software simulation, the establishment of a complete software platform. On the basis of this, the hardware realization of the system is explored. 


\section{Acknowledgements}

The work was supported by the 2014 hainan applied technology development and demonstration of special project (No. zdxm2014087); the key Laboratory of Sanya Project (No. L1410); the Agricultural Science and Technology Innovation Project of Sanya (No. 2015KJ15).

\section{References}

[1] Junmin Liu, Honghua Xu, Progress in Research Chinese Eaglewood, Journal of Chinese Medicinal Materials, Vol.28, No.7, pp. 627-632, 2012.

[2] Shaojun Huang, Aloes and Inferior Goods, China Practical Medicine, Vol.7, No.7, pp. 224-225, 2012.

[3] Jianli Zhong, WeiwenRao, Qinfeng Xie, Meng Wu, Study on Identification Method of Near Infrared Spectrum of Eaglewood, Northwest Pharmaceutical Journal, Vol.25, No.4, pp. 273-275, 2010.

[4] Kun Zhang, Shengpei Dai, Based on the Electronic Nose Technology of Tropical Agricultural Product Quality Distinguish Detection Technology Research, Software, Vol.33, No.8, pp. 90-93, 2012.

[5] Haifeng Wang, Honge Ren, Kun Zhang, Hongxu Wang, Mining Methods Based on Vague Optimization Evaluation, Advanced Materials Research, Vol. 659, pp. 128-133, 2013.

[6] Kun Zhang, Hongxu Wang, Haifeng Wang, Zhuang Li. The Time Series Prediction Algorithm of Enrollment based on the Hesitancy degree Correction Rule of Vague Sets, ICIC Express Letters, Vol.29, No.5, pp. 1311-1318, 2015.

[7] Jianli Zhong, WeiwenRao, Qinfeng Xie, Meng Wu, Study on Identification Method of Near Infrared Spectrum of Eaglewood, Northwest Pharmaceutical Journal, Vol.25, No.4, pp. 273-275, 2010 .

[8] Kun Zhang, Zhuang Li, Haifeng Wang, HongXu Wang. Fuzzy Time Series Prediction Model and Application based on Fuzzy Inverse, International Journal of Signal Processing, Image Processing and Pattern Recognition, Vol.8, No.10, pp. 121-128, 2015.

[9] Zhijun Li, Jingyi Ren, Hongrao Kuang, True and False Identification of Eaglewood, Journal of Chinese Medicinal Materials, Vol.34, No.1, pp. 59-61, 2011.

[10] Yuanqing Song, Yanping Wang, Jingyuan Mao, Exmination of Cellular Level Pulveizing Process of Eaglewood by Tlcs, Chemical Analysis and Meterage ,Vol.14, No.6, pp. 40-41, 2005.

[11] Haifeng Wang, Honge Ren, Kun Zhang, Texture Image Segmentation Algorithm on the Local Region Feature, ICIC Express Letters, Vol.8, No. 4, pp. 1193-1198, 2014.

[12] Haifeng Wang, Honge Ren, Kun Zhang, Study on the Bamboo Cross-Section Extraction Algorithm using Lab Color Space, The Journal of New Industrialization, Vol.4, No.9, pp. 44-49, 2014. 